\title{
Materialismo dialético, luta de classes e insights filosóficos sobre a educação a partir de Slavoj Žižek
}

\author{
Hildemar Luiz Rech \\ Fernando Facó de Assis Fonseca**
}

Resumo: O artigo aborda a concepção de luta de classes no atual cenário histórico, político e social. O dogma das democracias ocidentais sugere que vivemos numa era pós-ideológica. Isso implica que não há mais espaço para a ideia de luta de classes. Contudo, segundo Žižek, é esse discurso que deve ser enquadrado no campo ideológico. Žižek retoma o conceito de materialismo dialético a fim de demonstrar a contradição interna ao campo ideológico de nossa sociedade dita pós-ideológica. Nesse momento, o conceito de luta de classes retorna à cena. A luta de classes não consiste num antagonismo entre dois polos num espaço comum, mas na fissura inerente ao próprio espaço. Para desenvolver o tema, cabe, antes, abordar o conceito de materialismo teológico de Walter Benjamin, que fundamenta, substancialmente, o conceito de materialismo dialético de Žižek. Importante, igualmente, retomar uma reflexão sobre o conceito de pulsão de morte em Freud, já que tal conceito exprime exatamente a fissura interna à realidade que condiciona a luta de classes. Convém, ademais, compreender como a ideia de educação pode ser pensada a partir da contradição que mobiliza a luta de classes.

Palavras-chaves: Materialismo dialético. Luta de classes. Ideologia. Educação.

\footnotetext{
Doutor em Ciências Sociais pela Universidade Estadual de Campinas (UNICAMP). Professor na Universidade Federal do Ceará (UFC). E-mail: hluizrech@gmail.com. ORCID: https://orcid.org/0000-0002-5825-1887.

*** Doutor em Educação pela Universidade Federal do Ceará (UFC). E-mail: fernandofaco@hotmail.com.
} 


\title{
Dialetic materialism, class struggle and philosophical insights on education from Slavoj Žižek
}

\begin{abstract}
The article discusses the concept of class struggle in the current historical, political and social scenario. The dogma of Western democracies suggests that we live in a post-ideological era. This implies that there is no longer any room for the idea of class struggle. However, according to Žižek, it is this discourse that must be framed in the ideological domain. Žižek takes up the concept of dialectical materialism in order to demonstrate the internal contradiction to the ideological field of our so-called post-ideological society. At this point, the concept of class struggle returns to the scene. The class struggle does not consist of an antagonism between two poles in a common space, but in the fissure inherent in the space itself. To develop the theme, it is first necessary to approach Walter Benjamin's concept of theological materialism, which substantially supports Žižek's concept of dialectical materialism. It is also important to resume a reflection on the concept of the death instinct in Freud, because this concept expresses exactly the internal fissure in reality which conditions the class struggle. In addition, it is important to understand how the idea of education can be thought of from the contradiction that mobilizes the class struggle.
\end{abstract}

Keywords: Dialectical materialism. Class struggle. Ideology. Education.

\section{Matérialisme dialetique, lutte de classe et insights philosophiques sur l'éducation de Slavoj Zižek}

Résumé: L'article aborde le concept de lutte des classes dans le scénario historique, politique et social actuel. Le dogme des démocraties Occidentales sugère que nous vivons à une époque post-idéologique. Cela implique qu'il n'y a plus de place pour l'idée de lutte de classe. Cependant, selon Žižek, c'est ce discours qui doit être cadré dans le domaine idéologique. Žižek reprend le concept de matérialisme dialectique afin de démontrer la contradiction interne au champ idéologique de notre soi-disant société post-idéologique. À ce moment, le concept de lutte des classes revient sur la scène. La lutte des classes ne consiste pas en un antagonisme entre deux pôles dans un espace commun, mais dans la fissure inhérente à l'espace lui-même. Pour développer le thème, il est d'abord nécessaire d'approcher le concept de matérialisme théologique de Walter Benjamin, qui étaye 
substantiellement le concept de matérialisme dialectique de Žižek. Il est également important de reprendre une réflexion sur le concept d'instinct de mort chez Freud, car ce concept exprime exactement la fissure interne à la réalité qui conditionne la lutte des classes. En outre, il est important de comprendre comment l'idée de l'éducation peut être pensée à partir de la contradiction qui mobilise la lutte des classes.

Mots-clés: Matérialisme dialectique. Lutte des classes. Idéologie. Éducation.

\section{Introdução: a era pós-política}

A década de mil novecentos e noventa (a era pós-queda do muro de Berlim) foi um período marcado pela crise do conceito de política. No seu lugar, surgiu um sistema neutro e impessoal de regulação administrativa e burocrática da vida cotidiana, individual e coletiva. Para ser mais direto, a divisão do mundo em dois grandes blocos econômicos que estruturaram a geopolítica no pós-guerra deu lugar à hegemonia do modelo de gestão - social, político e econômico - das democracias capitalistas do mundo ocidental. No entanto, apesar disso (ou devido a isso), esse período foi, na mesma medida, um período intelectualmente propício para estabelecer os contornos teóricos que conduziriam - por uma lógica minimamente discernível - os desdobramentos sócio-políticos que alteravam a ordem estabelecida até então. É, portanto, nesse contexto que surgem, por exemplo, pensadores como Francis Fukuyama e Samuel Huntington. Cada um, ao seu modo, propôs uma nova compreensão das coordenadas determinantes da nova ordem mundial à la fin de siècle.

Desse modo, no seu The End of History and the Last Man, Fukuyama (1992) defende de que a fórmula final da melhor ordem social possível fora encontrada no modelo de democracia neoliberal capitalista. Estava claro, para ele, que a partir de então já não poderia haver sistema político mais avançado. Na melhor das hipóteses, restariam apenas obstáculos empíricos a serem ultrapassados. Enquanto isso, Huntington (2010), no seu Choque de Civilizações, alega que o mundo atual se 
organizaria não mais a partir de fatores ideológicos, políticos ou econômicos, mas por meio de fatores essencialmente culturais.

A razão pela qual somos levados a colocar lado a lado esses dois autores tem a ver com o modo como cada um entende o conceito de história. Assim, se temos, de um lado, Fukuyama, com o fim da história, de outro, com Huntington, a história continua, mas passa a ser compreendida em termos de choques entres civilizações. Porém, o que aparentemente aqui é interpretado enquanto visões teóricas divergentes, não passa, na verdade, de uma única e mesma leitura do mundo no período pós-Guerra-Fria: o choque entre civilizações é, em última instância, o fim da história, na medida em que a nova ordem estabelecida é considerada, por ambos os pensadores, como sendo formalmente pós-ideológica. O que Huntington não percebeu é que "choques entre culturas" não alcança o sentido de história propriamente dito, marcado por disputas ideológicas e lutas entre classes. Isso nos leva a constatar que, para Huntington, sua tese sobre as lutas entre civilizações consiste, no fundo, no fim da história propriamente dita, ainda que disfarçada de disputas étnicas e culturais.

De acordo com Žižek (2012c), o que caracteriza o conceito de história é justamente a tensão entre a história e o seu núcleo traumático ahistórico. Não podemos caracterizar a história com base apenas na sequência de lutas e mudanças ocorridas no nível de conflitos culturais, uma vez que a verdadeira essência da história envolve uma noção de ruptura radical, uma ruptura entre o antes e o depois.

Como diz Žižek (2012c, p. 169), essa "ruptura, no continuum da evolução, é a marca da história". De tal modo, a história, na acepção da palavra, não é outra coisa senão a sucessão de tais rupturas que redefinem o próprio sentido de história. Logo, apesar da inclinação imediata em censurar Fukuyama e concordar com Huntington (assinalando que a história continua, observando, por exemplo, que os conflitos étnicos ainda assombram a promessa de harmonia mundial), devemos antes conceder um crédito a Fukuyama, e aceitar que sua noção de que o "fim da história" possui uma verdade implícita, uma vez que esta ideia apresenta-se "mais próxima da abordagem histórica verdadeira do que o historicismo 
globalizado simplista (i.e., o contra-argumento ingênuo de que a história está longe de estar terminada, que as lutas e as mudanças continuam)" (ŽIŽEK, 2012c, p. 169).

No entanto, isso não é tudo. Ainda é preciso dialetizar Fukuyama. Apesar de ele pensar a história enquanto horizonte de sentido ideológico que caracteriza os momentos de luta anteriores ao modelo de democracia neoliberal - e não no sentido ingênuo de sequência infindável de acontecimentos - ele ainda permanece preso ao historicismo vulgar na medida em que se recusa a pensar o próprio horizonte de sentido ideológico que caracteriza nossa era pós-ideológica. Para superar esse limite, ele precisaria pensar o núcleo a-histórico oculto que estrutura o "fim da história". Mas como fazer isso sem que sejamos apanhados novamente em uma luta sem sentido por ideais já ultrapassados? Ou seja, como recuperar o verdadeiro sentido de história, como rupturas estruturais que redefinem o campo de sentido de uma determinada época, aceitando integralmente o fato de que a história do século XX tenha chegado ao seu fim?

A questão também pode ser deslocada para o quadro da filosofia pós-metafísica. O ponto é: como recuperar o núcleo a-histórico da própria história sem cair novamente numa metafísica pré-crítica? Ou posto diferentemente, dado nossa condição secular, pós-metafísica, como então encontrar novamente o ponto de Arquimedes do pensamento reflexivo?

\section{O núcleo teológico-materialista da história em Benjamin e Žižek}

Žižek (2006a) endossa a existência de um núcleo a-histórico da história que escapa à sua própria inserção na história. Para tanto, ele diferencia historicidade de historicismo. Segundo ele,

$\mathrm{O}$ aspecto decisivo consiste na distinção entre a historicidade propriamente dita e o historicismo evolucionista. A historicidade propriamente dita implica uma relação dialética com um núcleo a- 
histórico que permanece o mesmo, não como uma essência subjacente, mas como uma espécie de rochedo em que tropeça qualquer tentativa da sua integração no interior da ordem simbólica. Este rochedo é a 'Coisa' enquanto 'a parte do real que sofre de significante' (Lacan): o real 'sofre' na medida em que é o trauma que não é possível articular em termos adequados na cadeia significante. No caso do marxismo, esse 'real' do processo histórico é a 'luta de classes', que constitui o fio condutor de 'toda a história até o presente': todas as informações históricas são outras tantas tentativas (falhadas, em última análise) de 'aburguesar' esse núcleo real. (ŽIŽEK, 2006a, p. 262).

Aqui, Žižek já nos fornece uma dupla pista do sentido políticorevolucionário desse núcleo duro da história, o cerne a-histórico da própria história: o famigerado ${ }^{1}$ conceito marxista de "luta de classes" e o conceito de Real lacaniano. Mas para melhor compreender o que Žižek quer dizer com "luta de classes" enquanto o Real, a Coisa, ou "rochedo em que tropeça qualquer tentativa de integração no interior da ordem simbólica", convém estabelecer um diálogo com outro pensador que, a seu modo, também articulou algo muito similar à concepção de Žižek. Trata-se do pensador alemão Walter Benjamin.

Nas suas teses sobre o conceito de história, Benjamin traça uma relação paradoxal entre teologia e materialismo. A propósito, diga-se de passagem, a noção de materialismo dialético em Žižek é profundamente devedora dessa concepção teológico-materialista de Benjamin. O distanciamento de Benjamin em relação ao denominado "marxismo vulgar" corresponde, em larga escala, também à diferença entre o materialismo dialético de Žižek e a visão ortodoxa de materialismo histórico em Marx. Nesse sentido, o ponto de partida para Benjamin e

\footnotetext{
1 "Famigerado" encontra-se aqui no sentido irônico, claro. Isso porque esse conceito já levantou tantas polêmicas entre marxistas e pós-marxistas sobre se ainda é ou não válido continuar defendendo a ideia de luta de classes na atualidade. Ou seja, cabe saber se hoje ainda é possível defender uma ideia de luta de classes e em que medida essa luta seria possível, em quais condições e quais seriam seus autores.
} 
Žižek, em oposição Marx (vulgarmente interpretado), é que o ato revolucionário não diz respeito a um progresso em direção ao futuro, mas, pelo contrário, consiste numa repetição redentora de todas as tentativas de emancipação fracassadas do passado. Ou seja, não se trata de encontrar um continuum entre história e progresso, mas de instaurar uma ruptura no seio da narrativa linear da história. Para utilizar uma linguagem propriamente benjaminiana, trata-se de fazer saltar pelos ares o tempo homogêneo do continuum histórico. Michel Löwy, em sua leitura das teses sobre o conceito de história de Benjamin, escreve que:

Ao contrário do marxismo evolucionista vulgar - que pode se referir evidentemente a alguns escritos dos próprios Marx e Engels - Benjamin não concebe a revolução como o resultado 'natural' ou 'inevitável' do progresso econômico e técnico (ou da 'contradição entre forças e relações de produção'), mas como a interrupção de uma evolução história que leva à catástrofe (LÖWY, 2005, p. 23).

É significativo o fato de que "As teses sobre o conceito de história" de Benjamin ter causado tanto embaraço na comunidade intelectual de sua época, especialmente aos membros da Escola de Frankfurt, uma vez que o esperado por eles seria uma aproximação cada vez maior entre Benjamin e Marx. Entretanto, esse contínuo é abruptamente interrompido quando As Teses de Benjamin subitamente levantam uma problemática teológica no seio do materialismo histórico.

Vejamos, então, o que diz a primeira tese de Benjamin:

Conhecemos a história de um autômato construído de tal modo que podia responder a cada lance de um jogador de xadrez com um contralance, que lhe assegurava a vitória. Um fantoche vestido à turca, com um narguilé na boca, sentava-se diante do tabuleiro, coloca-o numa grande mesa. Um sistema de espelhos criava a ilusão de que a mesa era totalmente visível, em todos os seus pormenores. Na realidade, um anão corcunda se escondia nela, um mestre no 
xadrez, que dirigia com cordéis a mão do fantoche. Podemos imaginar uma contrapartida filosófica desse mecanismo. O fantoche chamado 'materialismo histórico' ganhará sempre. Ele pode enfrentar qualquer desafio, desde que tome a seu serviço a teologia. Hoje, ela é reconhecidamente pequena e feia e não ousa mostrar-se (BENJAMIN, 1996, p. 222).

Em suma, Benjamin sustenta que, embora o materialismo histórico sempre vença, ele só vence com o auxílio da teologia - termo este que, para os marxistas da época, possuía um sentido profundamente hediondo. Em sua leitura, Žižek (1988) confronta os dois níveis assimétricos da tese: "a alegoria tal como é lida na primeira parte" e "a interpretação que se fornece dela na segunda parte”. Ou seja, Žižek aponta para um desnível fundamental entre, de um lado, a composição formal do quadro e, de outro, o processo interpretativo da leitura dada no interior desse mesmo quadro. Nesse caso, a interpretação consiste no materialismo histórico que "toma a seu serviço a teologia”. Ao passo que a composição alegórica é a própria teologia (o anão corcunda) que puxa as cordinhas de dentro, e que comanda o "boneco" do materialismo histórico. Em outras palavras, isso quer dizer que, se por um lado, o conteúdo interpretativo nos leva a crer que é a teologia que está a serviço da história, por outro, a forma, ou a analogia, revela o contrário: é o anão quem na verdade puxa as cordinhas, é ele quem de fato comanda e manipula todo o processo. Neste caso, é a história que está a serviço da teologia.

Ora, o que seria o equivalente teórico dessa ideia senão a tese do significante de Lacan? Segundo Žižek (1988), da mesma maneira como materialismo histórico acredita vencer tomando a seu serviço a teologia, para Lacan, no campo do sentido, da hermenêutica, somos levados a crer que estamos sempre utilizando o significante como instrumento de significação. Ou seja, nesse nível percebemos o significante como um mero instrumento do significado. Ocorre que, num outro nível, da sincronicidade do significante, constatamos que o significado é sempre um efeito retroativo a posteriori submetido sempre à referência central do 
Significante-Mestre (S1). É fundamental atentar sobre esse aspecto da retroatividade do sentido.

De acordo com Žižek, a relação entre a forma alegórica em Benjamin e seu conteúdo segue o mesmo passo do efeito retroativo que caracteriza o processo de significação em Lacan. Mas no que exatamente consiste a dimensão teológica para Benjamin? Segundo Žižek (1988, p. 180), "trata-se de uma experiência absolutamente única, indicada pelo seguinte fragmento da herança de Benjamin: No Eingedenken, temos uma experiência que nos proíbe de apreender a história de um modo fundamentalmente ateológico". Deve-se, ante de mais nada, recusar todo e qualquer fundamentação hermenêutica aqui. Por isso, sempre quando Benjamin utiliza o termo Eingedenken, devemos rejeitar a livre tradução por rememoração ou reminiscência. Embora se trate de uma "apropriação do passado", não podemos - se quisermos compreendê-lo na acepção materialista do termo - permanecer no campo da interpretação do sentido. Nas palavras de Žižek (1988, p. 180), “a visão de Benjamin é inteiramente contrária ao postulado fundamental da compreensão hermenêutica (situar o texto interpretado na totalidade de sua época)".

Desse modo, para compreender o que Benjamin almeja dizer com Eingedenken, devemos conceber a apropriação do passado não como apropriação do significado mediante sua narrativa, mas como apropriação de um fragmento desse passado, de sua imagem dialética, que serve como fundamento teológico da história. Por isso que Eingedenken não assume uma forma impessoal e objetiva de apreensão do passado, um sentido totalizante e homogêneo da história, mas tem a ver com uma apropriação interessada por parte da classe subjugada. Nesse ponto, Benjamin é estritamente marxista. Para ele, a história é estruturalmente clivada entre, de um lado, uma classe dominante que estabelece a narrativa oficial e homogênea na linearidade do tempo, e, de outro, um excesso dessa mesma narrativa que não cessa de se inscrever na forma de lamentos daqueles que sucumbiram enquanto classe esmagada e oprimida.

Essa é a razão pela qual devemos refutar qualquer espécie de sentimentalismo nostálgico em relação ao passado no pensamento de 
Benjamin. O passado histórico que ele pretende enredar não é o passado tal como ele é contado pela narrativa hegemônica, mas o exato oposto: um passado que ainda não foi contado, mas que permanece latente, oprimido e soterrado nas ruínas da narrativa da história oficial. Por isso que, para o autor, em sua Tese XII, o único e verdadeiro "sujeito do conhecimento histórico é a própria classe combatente e oprimida" (BENJAMIN, 1996, p. 228).

Aqui, o leitor apressado certamente encontraria um nítido pretexto para introduzir, nessa ideia benjaminiana de história, o mote nietzschiano de "vontade de poder como interpretação", em cujo contexto o vencedor tem sempre o direito de contar sua própria história, de prescrever qual a perspectiva dominante etc. De acordo com Žižek (1988, p. 181), isso só seria correto caso Benjamin estivesse tratando de um antagonismo entre duas classes no interior de um mesmo plano, a partir do qual a classe dominante exporia sua história em detrimento da classe subjugada. Mas não é exatamente disso que se trata.

Essa concepção nietzschiana pode até ser válida para a classe dominante, mas não se aplica à classe subjugada. Existe entre elas uma assimetria fundamental, e Benjamin assinala isso a partir de dois modos de temporalidade: o tempo vazio homogêneo-contínuo (da historiografia dominante) e o tempo cheio, descontínuo (do materialismo histórico). No primeiro caso, o olhar historiográfico se restringe a contar apenas o que "realmente" aconteceu, como se a história fosse uma continuidade linear e homogênea, como uma corrente fechada. Nessa perspectiva, o olhar dos que venceram já é um olhar a priori, que determina formalmente o que deve permanecer dentro e o que deve ser rejeitado da narrativa oficial, dando aos fatos uma ordem e uma harmonia natural, linear e progressiva. E então, sob qual perspectiva se situa o tempo cheio do materialismo histórico?

Ao contrário do que somos conduzidos a pensar, o materialismo histórico não é simplesmente o outro lado da medalha, ou a mesma história sendo contada a partir de uma "outra perspectiva". Enquanto a historiografia dominante relata a história positiva dos grandes 
acontecimentos e bens culturais, o materialismo histórico, por sua vez, rejeita não somente o conteúdo positivo da historiografia dominante, mas fundamentalmente a própria forma vazia do tempo sobre o qual está fundada sua linha narrativa. Ou seja, para o materialismo histórico, a própria forma abstrata do tempo histórico já faz parte do conteúdo narrado pela classe dominante. Devemos, por isso, endossar as duras palavras de Benjamin, em sua tese VII (1996, p. 225), que diz: "lá onde há um documento cultural em memória dos grandes feitos históricos, reside também um documento de barbárie".

É certo que a classe dominante se apropria desse passado, forjando (para nós) um tempo linear através do qual passamos a compreender a coerência lógica dos acontecimentos históricos. Contudo, dizer que ela se apropria desse passado, que o prescreve segundo uma determinada narrativa hegemônica, deixa-nos uma estranha impressão de que esse passado também poderia ter sido contado diferentemente. $O$ caso é que, para Benjamin, essa outra história ainda não narrada permanece bastante viva, embora reprimida pela narrativa oficial. Ou seja, esse resto não assimilável do passado permanece, portanto, continuamente aberto, como uma potencialidade redentora das forças utópicas ainda não efetivadas. $\mathrm{O}$ tempo desse passado é, portanto, o tempo cheio, o tempo que pulsa por detrás da formalidade vazia do tempo cronológico-linear, isto é, um tempo saturado de agoras, de momentos no presente que aspiram à redenção. Como diz Benjamin, na Tese segunda (1996, p. 223), "O passado traz consigo um índice misterioso, que o impele à redenção".

E sendo esse passado ainda vivo, nossa questão premente passa a ser: como, então, se reapropriar dessa dimensão malograda do passado? Como libertar o passado do enclausuramento conferido pela própria história? Sabemos que não se trata de simplesmente ler a história por outro ângulo, invertendo os lados da medalha. Logo, a única solução plausível para essa apropriação consiste, segundo Benjamin, em sua Tese XIV, em cortar radicalmente a corrente contínua do desenvolvimento histórico, executando "o salto de tigre em direção ao passado" (BENJAMIN, 1996, p. 2030). Segundo Žižek, é nesse momento que Benjamin toca na 
assimetria fundamental entre o historicismo evolucionista, embasado no contínuo do movimento histórico, e o materialismo histórico, fundamentalmente teológico. Vejamos o que ele diz nas teses XVI e XVII, respectivamente:

O materialista histórico não pode renunciar ao conceito de presente que não é transição, mas para no tempo e se imobiliza. Porque esse conceito define exatamente aquele presente em que ele mesmo escreve a história. $\mathrm{O}$ historicista apresenta a imagem 'eterna' do passado, o materialista histórico faz desse passado uma experiência única. [...] Ele [o materialista histórico] fica senhor de suas forças, suficientemente viril para fazer saltar o continuиm da história [...] Pensar não inclui apenas o movimento das ideias, mas também sua imobilização. Quando o pensamento para, bruscamente, numa configuração saturada de tensões, ele lhes comunica um choque, através do qual essa configuração se cristaliza enquanto mônoda. Nessa estrutura, ele reconhece o sinal de uma imobilização messiânica dos acontecimentos, ou, dito de outro modo, de uma oportunidade revolucionária de lutar por um passado oprimido (BENJAMIN, 1996, p. 230-231).

Para Žižek, a capacidade do materialismo histórico de imobilizar o passado na forma de mônoda é precisamente o que distingue Benjamin do marxismo ortodoxo evolucionista. A mônoda consiste, portanto, em uma presença irredutível de um passado eterno, que corta transversalmente o curso evolutivo e linear da história. Mais uma vez, a verdadeira condição revolucionária não visa o futuro, mas remonta às circunstâncias passadas que malograram em consumar seu propósito redentor. Por essa razão, toda proposta redentora no presente é uma repetição reverberante das vozes abafadas que sucumbiram no passado. "A história é objeto de uma construção cujo lugar não é o tempo homogêneo e vazio, mas um tempo saturado de 'agoras"”, conforme a Tese XIV (BENJAMIN, 1996, p. 229).

É preciso apenas ter o devido cuidado para não interpretar a tese benjaminiana da mônoda, esse "passado atemporal", no sentido de um 
arcaísmo pré-histórico ou mitológico. Devemos compreendê-la fundamentalmente no sentido lacaniano da sincronia significante: "o elo entre a constelação passada e a constelação atual já não deve ser buscado na linha diacrônica, mas num curto-circuito paradigmático imediato" (ŽIŽEK, 1988, p. 183). Isso nos obriga, portanto, a repensar a eterna tensão entre idealismo e materialismo.

Conforme a doxa dominante, o historicismo evolucionista seria o modelo materialista par excellence, já que ele se apoia na história e na ordem natural dos eventos, ao passo que a tese teológica corresponderia ao modelo idealista, uma vez que pressupõe um núcleo a-histórico da própria história. Ocorre que, numa nova torção dialética, as coisas se apresentam sob uma nova luz: é o historicismo evolucionista que é, por definição, o modelo idealista, uma vez que a história contada é sempre a prioristicamente posta pelo olhar dos vencedores; enquanto que o verdadeiro materialismo é essencialmente teológico, pois identifica na própria linha da narrativa histórica (do tempo vazio) o núcleo recalcado sempre presente, não redutível ao tempo cronológico. Cumpre, portanto, compreender a mônoda não segundo uma metafísica da presença, um princípio último, doador de sentido e idêntico a si mesmo, mas sim como o momento de descontinuidade, de ruptura, que cristaliza a corrente linear da história porque nela repercute o passado recalcado, "impelido para fora do contínuo da história dominante" (ŽIŽEK, 1988, p. 183).

Segundo Žižek (1988), a aproximação entre a teoria da mônoda e a instância do significante é, portanto, mais do que evidente: o isolamento da mônoda em relação à linha do tempo corresponde exatamente à suspensão do Significante-Mestre do campo do sentido. Em outros termos, a suspensão da totalidade de sentido pela mônoda é o correlato teórico da tese lacaniana da sincronia do significante, segundo a qual todo o processo causal que define o sentido da história corresponde, por definição, a um efeito retroativo operado por um significante central: o $S_{1}$.

O ponto crucial é que, dessa perspectiva, a teologia benjaminiana, longe de representar um dogmatismo metafísico, pré-crítico, condiz precisamente com a tese materialista mais radical: para todo sentido 
histórico, é preciso que haja um núcleo recalcado subjacente, sustentando sua esfera simbólica. Por isso que o não-Todo é, a rigor, a forma mais adequada de apreender a verdadeira universalidade: enquanto o Todo corresponde à totalidade do campo do sentido, o não-Todo inclui nessa totalidade a sua própria dimensão recalcada. Ou seja, o não-Todo do materialismo teológico de Benjamin equivale, segundo Žižek, à noção de Absoluto hegeliano enquanto identidade da identidade com a não identidade. Em outros termos, o verdadeiro materialismo histórico é aquele que incorpora consigo o seu núcleo teológico recalcado, o elemento não idêntico que é excluído do campo hegemônico de sentido.

Desse modo, o materialismo de Benjamin se caracteriza por dar voz a um passado oprimido, posto à serviço da narrativa oficial da história. Então, o impasse da significação - essa lacuna antinômica que impede que a realidade seja um Todo harmonioso pleno de sentido - é, por assim dizer, o grito sufocante desse passado, cuja potencialidade ainda está por ser plenamente efetivada. Contudo, resta-nos ainda uma pergunta crucial: considerando o núcleo teológico da história, como, então, articular a relação entre passado, presente e futuro? Ou seja, como pensar esse "salto de tigre em direção ao passado", efetivado no presente, capaz de provocar uma abertura radical em relação ao futuro?

Antes de tudo, devemos confrontar duas concepções de futuro, que se deixam nitidamente transparecer na diferença aberta pela língua francesa entre futur e avenir. Jacques Derrida (2002) estabelece uma divergência precisa entre esses dois termos. Para o filósofo, o termo futur tem a ver com a ideia de programa, de um hoje que automaticamente se processa no amanhã, ou seja, um futuro orientado e prescrito conforme um cálculo feito a partir do presente. Segundo Derrida (2002), "O futuro assume aqui a dimensão de um futuro-presente, isto é, de um campo virtual já, de antemão, definido e configurado segundo as relações causais disponíveis no próprio presente". Por outro lado, avenir corresponde ao futuro na qualidade de uma alteridade radical, ou seja, um futuro-futuro, um futuro enquanto o advento do verdadeiramente novo, não programável ou prescrito. Segundo ele, existe, então, o futuro não previsível. Esse é o 
verdadeiro futuro, que é imprevisível (unpredictable). O outro que vem sem que eu possa mesmo esperá-lo. Então, se existe de fato um futuro, ele é o porvir (avenir), enquanto a vinda do outro lá onde não se possa mesmo prever.

Podemos, portanto, afirmar que a abertura de um verdadeiro futuro (enquanto avenir) depende estritamente da possibilidade de um corte, de uma ruptura profunda com relação às efetivações das tendências do presente. De que modo? A partir de um resgate do passado. As nossas preocupações com $\mathrm{o}$ futuro só têm realmente validade quando confrontadas com o passado, com suas potencialidades redentoras sucumbidas, as únicas capazes de (re)conduzir o presente em direção a um futuro radicalmente novo, imprevisto e - por que não? - impossível. Por essa razão, o verdadeiro futuro não corresponde ao tempo verbal do futuro do presente, mas ao futuro do pretérito. Essa é a razão pela qual o mote da ação revolucionária propriamente dita não consiste em dizer "as coisas serão assim ou assado", mas "as coisas teriam sido assim ou assado (...se tivéssemos ousado tomar outro caminho etc.)". Ou seja, a fim de concretizar uma mudança efetiva no encadeamento dos fatos, é preciso, primeiramente, projetar-se no futuro programado, previsível, e tomar como certo a catástrofe que se aproxima numa contagem regressiva e implacável. Ao constatar o desastre consumado, a hecatombe provocada por nossas ações, o segundo passo consiste, então, em voltar ao passado (nesse caso, o presente) e (re)pensar o que poderia ter sido feito para evitar o colapso.

Nesse sentido, a ação revolucionária é sempre uma ação ao mesmo tempo reflexiva e engajada de como agir no presente como se esse fosse sempre-já o próprio passado, uma vez que o futuro, na perspectiva do tempo vazio, é a simples projeção virtual de nossas ações no tempo presente. Por isso, agir no presente como se este fosse o próprio passado significa, na linguagem benjaminiana, resgatar o potencial do passado inscrito no presente sob a forma de mônoda, isto é, dar voz às ruínas soterradas pela visão hegemônica do presente e, assim, fazer parar o trem 
da história, abrindo a possibilidade do verdadeiro "por vir" de uma alteridade radical ${ }^{2}$.

Cabe ser ainda mais preciso nesse ponto. Esse retorno ao passado redentor não significa simplesmente lamentar o que aconteceu e agir a partir de agora da forma correta, como se pudéssemos ter agido assim desde a primeira vez. Longe disso, essa torção dialética só pode se efetivar tendo como pano de fundo a escolha errada. Ou seja, a escolha correta só é possível da segunda vez, "pois somente a primeira escolha, em sua condição de erro, literalmente cria as condições para a escolha certa" (ŽIŽEK, 2012a, p. 317). O fundamental aqui é abrir o campo de possibilidade a partir da pura efetividade. Encontramo-nos aqui no seio da reviravolta ontológica formulada pelo idealismo alemão: diferentemente da ontologia aristotélica padrão que supunha um vetor que vai da possibilidade à efetividade, deveríamos pensar a dimensão da potencialidade como um efeito retroativo em relação à mera efetividade, desenterrando "no próprio cerne da efetividade, uma aspiração secreta à potencialidade" (ŽIŽEK, 2012a, p. 316). Assim, "a ideia de que já poderíamos fazer a escolha certa da primeira vez, mas simplesmente perdemos a chance por causalidade, é uma ilusão retroativa" (ŽIŽEK, 2012a, p. 317).

\section{A antinomia da Pulsão em Freud}

Diante disso, como então incluir a ideia de luta de classes no interior do próprio tecido histórico? A primeira providência a ser tomada aqui é rejeitar rigidamente o velho bordão pseudomarxista que percebe o conceito de luta de classes como sendo um conflito entre duas classes no interior de uma dada realidade social. Percebemos agora, segundo a perspectiva teológica-materialista benjaminiana, o quanto essa visão é

\footnotetext{
${ }^{2}$ Aos liberais-progressistas que sempre veem uma luz no fim do túnel quando tudo na realidade vai mal, poderíamos, todavia, oferecer-lhes uma resposta bem à altura de seu cinismo: sim, claro, há sempre uma luz no fim do túnel; mas essa é a luz do farol do trem da história, que avança inexoravelmente em nossa direção.
} 
inconsistente. A própria concepção de realidade, nesse caso, já é um pressuposto articulado pela narrativa oficial da classe dominante, isto é, da burguesia. Portanto, quando se fala em luta de classes, não cabe mais articular uma realidade neutra em cujo espaço trava-se a luta entre duas classes antagônicas. O ideal de neutralidade já é, em si, um princípio formalmente faccioso, pois consiste na própria violência hedionda semprejá operada pela classe favorecida.

É preciso retomar aqui o conceito de pulsão de morte para a psicanálise, o ponto em que Freud substitui a tese do dualismo pulsional. Quando Freud introduz o dualismo da pulsão de morte versus pulsão de vida, não podemos mais falar de forças antagônicas, mas de uma lacuna antinômica situada no coração da pulsão. Ou seja, a pulsão de morte não representa um vetor contraposto ao vetor da pulsão de vida. Lidamos agora com um único vetor, mas cindido em si mesmo por uma lacuna imanente. Em outras palavras, a pulsão de morte é a própria cisão, a lacuna imanente, uma tensão interna que age silenciosamente, e cujo efeito introduz, no equilíbrio homeostático da vida, uma descontinuidade periódica. Como o próprio Freud intuiu de maneira formidável:

O princípio do prazer parece mesmo estar a serviço dos instintos de morte; é certo também que vigia também os estímulos de fora, avaliados como perigosos pelas duas espécies de instintos, mas, sobretudo, os aumentos de estímulos a partir de dentro, que chegam a dificultar a tarefa de viver (FREUD, 1920/2010, p. 238).

Segundo a perspectiva žižekiana, é como se a pulsão de vida fosse uma tentativa exasperada de manter uma paz harmônica, o equilíbrio entre a libido e o princípio de realidade, enquanto que a pulsão de morte consistisse no impasse constitutivo dessa ordem, a tensão imanente que desequilibra o acalentador ponto de homeostase entre esses dois princípios. Devemos, então, compreender o estatuto da pulsão de morte, conforme assinala Žižek (2011, p. 46) "como uma tendência mais radical de um organismo vivo em manter um estado de tensão, para evitar o 
'relaxamento' final da conquista de um estado de homeostasia completa". Ou seja, a pulsão de morte, no sentido de um "além do princípio do prazer", é, portanto, essa inclinação primordial constituinte de um organismo em repetir infinitamente o estado de tensão ${ }^{3}$. Portanto, é preciso ter em mente que a "pulsão de morte não é um corpo estranho, um intruso que perturba o circuito harmonioso do aparelho psíquico em busca pelo 'princípio do prazer'” (ŽIŽEK, 2008b, p. 55). Isso equivale a dizer que nada lhe é externo, mas estritamente inerente a ele. E o efeito paradoxal é inevitável aqui: no exato momento em que suspendemos a pressão da realidade externa, a pedra no caminho que frustra a plena satisfação do desejo, o resultado não será - como é de se esperar - o acesso desimpedido ao princípio do prazer.

$\mathrm{Na}$ verdade, quando entregue ao seu livre curso, o psiquismo continua contraintuitivamente a circular de forma ininterrupta em torno de um ponto traumático primordial, boicotando, assim, sistematicamente, a satisfação. Desse modo, o empecilho sobre o qual tropeçamos, e que nos impede de alcançar a harmonia almejada pelo princípio do prazer, longe de ser um contraponto externo, é totalmente imanente ao ideal homeostático do psiquismo, ou seja, à condição positiva do seu desejo de completude. Caso esse bloqueio seja suspenso, o equilíbrio que move o desejo e, consequentemente, o princípio de prazer, perde completamente sua razão de ser.

Portanto, o espaço do desejo, como afirma Žižek (2006a), é um espaço curvo, que contorna indefinidamente seu objeto empírico imediato, ou seja, ele segue um movimento circular numa repetição infindável em torno de seu alvo. A única maneira de alcançar seu objeto é por uma via indireta, por um caminho desviado, cheio de meandros. O procedimento

\footnotetext{
${ }^{3}$ Mesmo que Freud tenha apontado certeiramente para essa conclusão, ele se equivoca quando equipara o conceito de pulsão de morte com a tese budista do princípio do nirvana. É como se nem mesmo Freud tivesse sido capaz de abarcar a complexidade desse conceito. Como afirma Žižek (2012a, p. 646), em outro lugar: "nem mesmo Freud apreendeu isso com clareza, às vezes confundindo a pulsão de morte com o "princípio do nirvana", portanto não vendo o cerne de sua noção de pulsão de morte como a imortalidade obscena "não morta" de uma repetição que insiste para além da vida e da morte".
} 
direto garante que não acertaremos no alvo. Esse desvio (que podemos considerar como sendo ontológico), cujo efeito faz com que o objeto do desejo nunca seja saciado, é denominado por Lacan como mais-gozar. Ou seja, o gozo não é a saciação do desejo no encontro com seu objeto, mas justamente o que mantém o desejo pela distância de seu objeto. Isso é de extrema importância para compreendermos, no próximo ponto, como a relação da burguesia com a "classe" oprimida é uma relação pulsional de mais-gozar.

\section{Luta de classe e política da subtração}

Para Žižek, o conceito de luta de classes segue o mesmo princípio: não se trata de um conflito entre duas classes: a classe dominante e a classe oprimida. No fundo há uma só classe, a burguesia, e a luta trava-se no interior de seu próprio terreno, entre o ideal harmônico idealizado e seu impasse constitutivo (reprimido). Como escreve Žižek (2012b, p. 280),"luta de classes não significa que a sociedade é composta de classes que lutam entre si, mas que, sob o disfarce da luta de classes, a sociedade enfrenta suas [próprias] limitações".

Conhecemos a lição básica do pensamento marxista: as contradições inerentes à sociedade burguesa não são meras contingências que podem ser reguladas com base num esforço coletivo e participativo de todos; tais contradições são constitutivas do próprio modelo de sociedade burguesa. Elas constatam a inexistência de um Todo harmonioso que remete cada indivíduo a seu lugar apropriado na cadeia ontológica da ordem social. O princípio de liberdade formal da sociedade burguesa rompe drasticamente com essa hierarquia orgânica previamente estabelecida. E aqui tocamos no núcleo do paradoxo constitutivo da sociedade burguesa. Na medida em que ela incide uma lacuna irredutível na ordem do Todo (o princípio formal de liberdade), ela se recusa a abdicar do próprio ideal de uma totalidade harmônica. Em termos propriamente psicanalíticos, a burguesia goza compulsivamente de seu próprio fracasso constitutivo. Eis a razão pela qual ela é essencialmente 
perversa. Quanto maior o antagonismo social, maiores são as promessas de uma sociedade harmônica; quanto maior o impasse social, mais intenso é o gozo sobre o seu próprio impasse. Ou seja, o que mantém a fantasia de completude é a própria cisão. Segundo Žižek,

[A luta de classes] torna a sociedade 'inconsistente', antagônica, e perturba seu equilíbrio; contudo, ela é também o que mantém unido todo o corpo social, seu princípio estruturador subjacente, posto que todos os fenômenos são sobredeterminados pela luta de classes. Em um nível mais prosaico, não é a própria luta de classes, uma tensão básica, que em geral mantém unidos elementos diferentes? (ŽIŽEK, 2012a, p. 413).

É nesse sentido exato que Žižek (endossando a tese de Lacan) insiste no fato de que foi Marx quem inventou o sintoma: antes mesmo de Freud articular a ideia de sintoma como a exceção constitutiva do Eu, como o corpo estranho, não assimilável, que, no entanto, sustenta a imagem ilusória de uma autoidentidade subjetiva, Marx já havia tematizado essa mesma lógica da exceção constitutiva em outro plano:

A grande realização de Marx foi demonstrar como todos os fenômenos que se afiguram à consciência comum como simples desvios, simples deformações e degenerações contingentes do funcionamento 'normal' da sociedade (crises econômicas, guerras etc.) - e, como tal, facilmente elimináveis por uma melhoria no sistema -, são produtos necessários do próprio sistema, ou seja, são os lugares em que transparece a sua 'verdade', seu caráter antagônico imanente (ŽIŽEK, 1992, p. 125).

Então, qual seria a solução para os antagonismos sociais, que constituem a base irredutível da própria sociedade burguesa? Ou, em outros termos, qual seria o passo para a verdadeira política da reconciliação? Sigamos essa pista a partir da ideia de política da subtração, formulada por Alain Badiou, segundo a perspectiva de Žižek. 
Uma ação verdadeiramente revolucionária, de acordo com essa concepção política, não vê, a fim de promover uma reformulação significativa no estado de coisas vigente, a necessidade do menor derramamento de sangue, ou mesmo de um engajamento brutal pela tomada de poder. De modo peculiar, essa política não é propriamente destrutiva, antagônica, nem mesmo militarizada. Trata-se de um gênero de revolução passiva (mas que, quando tomada numa acepção mais profunda, torna-se mais violenta que qualquer violência no plano empírico). Essa política, por conseguinte, não tem como alvo o centro do poder administrativo, tampouco tem o propósito de destituir líderes governamentais específicos; a grande revolução aqui incide diretamente no registro simbólico, esfera responsável por integrar a realidade num todo coeso.

Em outras palavras, a ideia de subtração revolucionária aqui em jogo tem como tarefa atuar diretamente no próprio quadro categorial que determina a coerência interna da esfera intramundana - o jogo dos elementos no interior da forma total. Como ressalta Žižek (2011, p. 404), "em vez de destruir-negar diretamente o poder dominante, permanecendo em seu campo, ela solapa esse mesmo campo, criando um novo espaço positivo".

A subtração burguesa, enquanto negação abstrata, segue o modelo paradigmático da figura de consciência hegeliana da "Bela Alma". Segundo Žižek (1992, p. 86), a "Bela Alma” fala, exprime suas convicções profundas deplorando o triste estado no mundo, as injustiças etc. Não pretende "sujar suas mãos", mas manter-se a qualquer preço longe do mundo prosaico. A "Bela Alma" se revela como uma "[...] alma terna, estetizante, requintada demais para a vulgaridade do mundo social" (ŽIŽEK, 1992, p. 86). Mas não percamos de vista o essencial: de acordo com Žižek, a crítica hegeliana à "Bela Alma" não se limita apenas em condená-la por falar e não agir, "[...] por contentar em deplorar o estado do mundo sem nada modificar nele" (ŽIŽEK, 1992, p. 86).

Logo, a falsidade da "Bela Alma" não reside tanto em sua inatividade política que, no lugar de agir para mudar o mundo que deplora, 
opta apenas pela consternação passiva. A rigor, sua fraude consiste na maneira como que essa inatividade torna-se plenamente responsável por estruturar, prefigurar, contraintuitivamente, a própria ordem objetiva de seu mundo social. Em outras palavras, é como se, no momento em que assume para si o papel de vítima suprema, a "Bela Alma" postulasse, retroativamente, a base formal da dinâmica intersubjetiva pela qual ela se reconhece.

Por isso, é fundamental inserirmos aqui o quadro formal que constitui o conteúdo narrativo como sendo parte do próprio conteúdo. Isto é, diferentemente da forma transcendental que delimita o campo do sentido por meio de uma síntese a priori para o pensamento propriamente dialético. De acordo com Žižek (2012a), a tensão entre forma e conteúdo deve ser refletida de volta no próprio conteúdo. Assim, somos tentados a afirmar que a grande cilada do idealismo transcendental, em Kant, é pressupor uma forma de mediação não mediada, isto é, pressupor uma síntese a priori de todo conteúdo específico sem se perguntar pelo processo mediador da própria síntese. Mas conforme a visão materialista que articulamos aqui, a própria forma transcendental deve ser dialeticamente mediada: a forma que dá consistência ao conteúdo é postulada retroativamente a posteriori no intuito de dar consistência à incompletude ontológica da própria realidade. Ou ainda, a forma transcendental advém somente para encobrir a inconsistência do campo do sentido, para selar a lacuna imanente constitutiva da própria realidade.

Nesse sentido, a autocomiseração da "Bela Alma" determina antecipadamente o seu lugar de sofredora: cega pelo brilho ofuscante do destino, ela esquece a sua responsabilidade formal diante do estado de coisas vigente. Somos, diante disso, tentados a inferir uma tese paradoxal: o sofrimento da "Bela Alma" é ilegítimo não porque ele é inexistente enquanto puro fingimento ou manipulação teatral -; mas pelo contrário: seu sofrimento é ilegítimo porque ele de fato existe - fenomenalmente falando. O paradoxo aqui se explica pelo fato da própria existência de algo estar submetida a um processo formal de síntese a priori. Assim, para assinalar o lugar de vítima, é preciso antes de tudo estabelecer uma 
pseudo-distância entre a forma pura do olhar vitimado e o conteúdo da realidade opressora.

O caso aqui segue a mesma lógica do caso do "marido ciumento", conforme a análise de Lacan. Mesmo que as acusações a respeito da infidelidade de sua esposa sejam verdadeiras, ainda assim o seu ciúme é patológico. Não é o seu ciúme que se justifica com base nos fatos da realidade, mas é ele que justifica, a priori, o enlaçamento da rede significante. De forma homóloga, por mais que a opressão sobre a "Bela Alma" seja verdadeira, o que é encoberto aqui é a necessidade estrutural dessa opressão para que, desse modo, seja mantida sua posição ideológica. Em suma, o a priori é, antes de tudo, um princípio performativo, e não constatativo, ou seja, trata-se de uma atitude fundamentalmente performativa que agencia a constituição dos fatos da realidade pela posição de gozo assumida aprioristicamente pelo sujeito ${ }^{4}$. Assim, "a aparência de uma constatação dos fatos dissimula uma cumplicidade, o consentimento ou a vontade ativa de endossar esse papel e, dessa maneira, permitir à situação deplorada que se reproduza." (ŽIŽEK, 1992, p. 86).

Este gesto drástico de renúncia total exigido à "Bela Alma" é o real fundamento do ato político. De tal modo, o verdadeiro sacrifício consiste num gesto de total identificação com o seu sintoma:

Identificar-se com o sintoma significa reconhecer nos 'excessos', nos descarrilamentos do curso 'normal' das coisas, a chave que nos dá acesso a seu verdadeiro funcionamento - exatamente como Freud, para quem as chaves do funcionamento do aparelho psíquico

\footnotetext{
${ }^{4}$ Cumpre destacar que estamos lidando aqui com uma lacuna irredutível no cerne da subjetividade. Isso significa que, quando dizemos que o a priori é fundamentalmente um princípio performativo, não queremos defender aqui um idealismo dogmático - tese segundo a qual a realidade consiste apenas num produto da mente criativa do sujeito. Nosso ponto de vista é estritamente dialético. Ou seja, a condição performativa propriamente dita entra em cena somente como uma torção dialética sobre o princípio de constatação, como? - ao reconhecer que a objetividade da realidade nada mais é do que uma justificativa para o excesso de jouissance, o mais-gozar, produzido pelo próprio sintoma do sujeito: a realidade que me oprime é meio pelo qual incorre meu gozo [...].
} 
eram os sonhos, os lapsos e outros fenômenos 'anormais' similares (ŽIŽEK, 1992, p. 125).

Há aqui, nesse gesto de identificação com o sintoma, uma mudança estrutural com relação à posição da "Bela Alma". Tocamos, desse modo, no núcleo da verdadeira política da subtração. A essência da política da subtração não é a forma burguesa da negação abstrata, mas a da negação determinada expressa na figura do proletariado. Então, como pensar a condição do proletariado segundo essa perspectiva? Sabemos que não basta conceber o proletariado como sendo "o outro" da burguesia. Por esse ângulo, seríamos novamente apanhados por uma visão estreita de luta de classes contra o pano de fundo de uma realidade neutra e impessoal. Por isso, devemos pensar o proletariado como sendo a identificação com o próprio sintoma da burguesia, "o excesso que descarrila o curso normal das coisas".

É preciso conceber as coisas segundo a perspectiva do materialismo dialético de acordo com a leitura que Žižek faz de Hegel. De acordo com Žižek, na dialética hegeliana, não há necessidade de considerar um terceiro elemento que unifique, numa síntese mais elevada, os dois polos de uma determinada oposição. "Para Hegel, o objetivo não é (r)estabelecer a simetria e o equilíbrio dos dois princípios opostos, mas reconhecer em um polo o sintoma da falha do outro (e não vice-versa)" (ŽIŽEK, 2012a, p. 148). Devemos romper definitivamente com a classificação aristotélica entre gênero (universal) e suas espécies (particular). Mas isso não significa aceitar a solução pós-moderna que simplesmente elimina o campo do universal em função da pluralidade dos particulares - que coincide com a solução neoliberal-multiculturalista. $\mathrm{Na}$ perspectiva da dialética hegeliana, o próprio gênero já é uma de suas espécies: a luta entre dois polos não é um simples antagonismo, mas a antinomia fundamental entre os particulares e o próprio gênero encarnado numa das espécies. Como diz Žižek,

A universalidade concreta é exatamente a universalidade que se inclui entre suas espécies, 
disfarçada de um momento singular que carece de conteúdo particular - em suma, são justamente aqueles que não têm lugar apropriado no Todo social [...] que representam a dimensão universal da sociedade que os gera (ŽIŽEK, 2012a, p. 285).

Portanto, é infame pensar que a burguesia e a classe oprimida são duas espécies de um mesmo todo lutando entre si. A classe oprimida já é o próprio gênero (universal) como contradição interna da classe burguesa. Em outras palavras, a classe oprimida, segundo o modelo dialético, propriamente materialista, seria a espécie que, justamente por carecer de um lugar apropriado no interior da ordem social estabelecida, representa $o$ próprio gênero universal. Em contrapartida, a classe burguesa, por sua vez, representa a espécie propriamente falando, cujo lugar apropriado na sociedade depende fundamentalmente da negação sistemática da classe oprimida, considerando-a como um obstáculo a ser superado, enquanto polo opositor. Portanto, a antinomia, a lacuna que impede a classe burguesa de se consolidar como um todo harmônico e idêntico a si mesmo - como uma universalidade abstrata -, é a própria universalidade concreta encarnada pelo proletariado.

Assim, a diferença entre a universalidade abstrata burguesa e a universalidade concreta, expressa na figura do proletariado, consiste em que esta última incorpora a própria dimensão da subjetividade engajada no processo de luta emancipatória. A universalidade concreta é, portanto, o próprio corte imanente na ordem da universalidade abstrata, o excesso constituinte (teológico, para falar com Benjamin), que impede que um particular seja plenamente identificado com ele mesmo. Em outras palavras, a universalidade concreta é a universalidade que incorpora na própria ordem positiva do ser o seu excesso constituinte, elevando, assim, o contingente - o obstáculo que impede o acesso direto à totalidade harmônica do ser - à própria condição de universalidade.

Mas há ainda um detalhe que precisa ser mais bem esclarecido: pensar o proletariado como a lacuna antinômica que impede à classe burguesa de realizar-se plenamente não significa dizer que sem ele a 
burguesia se fecharia sobre si mesma numa homogeneidade límpida e autotransparente. Essa totalidade homogênea é justamente a fantasia ideológica da burguesia, seu sonho dogmático; nesse caso, o fascismo, de acordo com Žižek, é a radicalidade desse devaneio burguês, quer dizer, o fascismo consiste na passagem ao ato da pura forma da fantasia burguesa na tentativa desesperada de abolir o excesso contingente que perturba a "ordem social",

Entretanto, se considerarmos o oposto, a fórmula torna-se totalmente plausível: a burguesia corresponde à classe cuja forma impede o proletariado de realizar-se plenamente. Não se trata - repito - de uma teoria da compensação segundo a qual é preciso encontrar o ponto de equilíbrio entre os polos antagônicos; trata-se, sim, de um impasse constitutivo no coração da burguesia que luta contra si mesma para negálo, no intuito de manter intacta sua fantasia ideológica de completude.

Logo, se o proletariado é o sintoma da burguesia, o inverso é fundamentalmente falso: a burguesia jamais poderia ser um sintoma do proletariado! Desse modo, a fórmula correta para pensar a natureza do proletariado não pode ser simplesmente a não-burguesia, sua simples negação, mas, especialmente, a não não-burguesia, ou seja, a negação de sua própria negação ${ }^{6}$. Nesse sentido, se a classe oprimida é considerada

\footnotetext{
${ }^{5} \mathrm{O}$ fascismo é a loucura burguesa na sua forma pura e concreta, ou seja, a burguesia encontrando consigo mesma na forma de seu excesso constituinte, forçando, de maneira brutal e definitiva, o fechamento da lacuna inerente de seu próprio quadro ideológicofantasístico. Nesse sentido, a diferença entre uma verdadeira revolução comunista e o fascismo é que, enquanto este reivindica o apagamento de seu sintoma em nome da manutenção harmônica de seu quadro ideológico, a revolução comunista implica no seu exato oposto: é a própria totalidade harmônica do quadro ideológico que é deposta, em nome da universalidade concreta expressa na forma de sintoma social. A dialética nesse caso é radicalmente materialista, ou seja, no comunismo, a preocupação é fundamentalmente com o singular que caracteriza a universalidade concreta da "ordem social".

${ }^{6}$ É possível articular essa relação entre burguesia, classe oprimida e proletariado segundo a tríade hegeliana tese-antítese-síntese. Se começarmos com a tese de uma totalidade harmônica da sociedade burguesa, sua ideologia propriamente dita, sua antítese será evidentemente os impasses constitutivos dessa ordem, sua contradição interna estruturalmente necessária, representada, é claro, pela classe oprimida. Seria, então, a síntese o restabelecimento de uma normatividade legal em cujo estatuto a classe oprimida
} 
uma classe, ela o é somente na medida em que responde às necessidades ideológicas da classe burguesa, isto é, enquanto ela permanece como sendo "o outro" que mantém aberta a fantasia primordial da classe dominante. O fundamental aqui é pensar no processo de identificação com o sintoma, a mudança formal a partir da qual a burguesia "magicamente" se transforma no seu núcleo recalcado, na forma de sua própria universalidade concreta: o proletariado. Por isso que, para Lacan, "só existe um sintoma social: todo indivíduo é efetivamente proletário, ou seja, não dispõe de um discurso pelo qual possa estabelecer um elo social" (ŽIŽEK, 2012a, p. 286).

Com base nisso, Žižek afirma, “A verdade universal só é acessível a partir de uma posição subjetiva engajada parcial” (2008a, p. 53). Devemos atribuir toda carga política a essas palavras. A mudança da burguesia para a posição do proletariado não é absolutamente a destituição de uma classe por outra, mas um deslocamento através do qual o sujeito se inscreve na própria ordem positiva do ser, identificando-se agora com o próprio limite ontológico que submete a realidade a uma visão parcial e em devir.

Devemos pensar a reconciliação, em sua acepção propriamente hegeliana, não como numa intervenção direta na ordem dos fatos, e sim na esfera transcendental que abre a dimensão da realidade. Isso significa que a reconciliação como modo de resolver o impasse da "Bela Alma" não é propriamente uma transformação mágica dessa realidade, mas uma transformação "mágica" da própria postura subjetiva da "Bela Alma", pela "aceitação do caos e da injustiça do mundo como imanente à Bela Alma,

obtivesse finalmente o seu reconhecimento efetivo? De acordo com Žižek, devemos recusar radicalmente essa solução liberal-democrática. E por uma simples razão: porque essas seriam exatamente as condições da fantasia ideológica burguesa. Em contrapartida, do ponto de vista materialista-dialético, a classe oprimida não consiste num simples estorvo a ser suprimido, mas na condição mesma de possibilidade desse sonho dogmático burguês. Portanto, a síntese propriamente dialética aqui não poderia ser outro senão a afirmação incondicional da antítese, já que é a própria tese, isto é, a ideologia burguesa em seu aspecto formal, que deve ser suprimida em nome da universalidade da classe oprimida. Em outras palavras, a verdadeira síntese só pode ocorrer com a afirmação daquilo que, no plano ideológico da tese, é negado, e com a subsequente elevação da classe oprimida à condição de verdadeira universalidade, expressa, evidentemente, na figura do proletariado. 
que o deplora, ou a aceitação por parte da Bela Alma do fato de que ela participa da realidade que critica e julga" (ŽIŽEK, 2012a, p. 331). Por isso, é importante insistir no fato de que um ato político propriamente dito não implica necessariamente num rebuliço incessante na configuração interna do estado de coisas no mundo. A verdadeira mudança é fundamentalmente formal, ou seja, uma simples mudança de olhar sobre este mesmo estado de coisas.

No modo de negação burguesa permanecemos no interior dos limites simbólicos que condicionam meu olhar sobre o mundo, isto é, a negação aqui serve apenas para manter de pé as coordenadas ideológicas que definem a visão de mundo dominante. Entretanto, quando o sujeito encarna a própria negação, ocorre uma torção dialética que desloca não a organização interna da realidade, mas o próprio eixo que sustenta essa realidade, ou melhor, o ponto de vista transcendental (a universalidade abstrata) que garante sua coesão interna. Insisto: não se trata de transformar o mundo remanejando continuamente de lugar em lugar sua organização interna; a verdadeira mudança consiste na suspensão da moldura transcendental que configura o estado de coisas no mundo. A negação da negação, ou seja, a negação determinada, encarnada na própria ordem positiva, só é possível através do engajamento subjetivo radical, por meio do qual a própria forma a priori, transcendental, é introduzida no próprio conteúdo, provocando, assim, um curto-circuito inapreensível entre sujeito e objeto - ou, em termos lacanianos, entre a forma vazia do sujeito (\$) e seu correlato objetal, isto é, o resto inassimilável da jouissance (objeto $a$ ).

A política propriamente dita ocorre nesse espaço intermediário, em que a realidade se revela como ontologicamente incompleta, não-Toda. A fórmula correta, portanto, não é "tudo é política", mas "não-Tudo é política" (ŽIŽEK, 2012a, p. 342). Isso nos leva a concluir que todo ato político é, sempre e por definição, uma identificação com o lugar (ou melhor, a falta de lugar) do proletário, isto é: "o ato só pode surgir da posição 'proletária' de ser destituído de um discurso (de ocupar o lugar da 'parte de nenhuma parte' dentro do corpo social existente)" (ŽIŽEK, 
2012a, p. 286). Eis, portanto, o verdadeiro papel da luta emancipatória da esquerda:

A esquerda aceita simultaneamente o caráter antagônico da sociedade (não existe posição neutra, a luta é inevitável), e permanece universalista (tomando a palavra em nome da emancipação universal): na perspectiva da esquerda, aceitar o caráter radicalmente antagônico - quer dizer, político - da vida social, aceitar a necessidade de 'tomar partido' é a única maneira de se ser efetivamente universal [...] $\mathrm{O}$ autêntico universalismo de esquerda não implica qualquer espécie de retorno a qualquer espessura universal neutra (uma noção como a de humanidade, etc.); faz antes referência a um universal que só chega à existência (que só advém 'a si próprio', para dizermos com Hegel) num elemento particular estruturalmente deslocado, 'desincluído': nos limites de um Todo social dado, trata-se precisamente do elemento que se vê proibido de atualizar a sua plena identidade particular representando a sua dimensão universal (ŽIŽEK, 2006b, p. 84).

Isso nos leva de volta ao tema da política da subtração. Nesse sentido, a verdadeira subtração política é aquela feita na base formal que funda um determinado campo hegemônico, sendo esta a única forma efetiva de intervenção política propriamente falando. É por esta razão que tal subtração é substancialmente violenta: não porque mata sujeitos e destrói monumentos, mas pelo simples fato de afetar violentamente o campo no qual estes elementos estão inscritos, "pondo a nu suas verdadeiras coordenadas" (ŽIŽEK, 2011, p. 406). A violência maior é, por assim dizer, aquela que age passivamente, transformando, como o olhar de Medusa, tudo a seu redor em matéria inerte e insignificante.

\section{Considerações sobre educação}

Apesar de Žižek não possuir em seu escopo teórico nenhuma ou quase nenhuma reflexão sobre o tema da educação, isso não significa que 
não podemos extrair de sua teoria algumas conclusões relevantes sobre o tema. Até porque, considerando o fato de a psicanálise ser um de seus pilares teóricos, podemos, com efeito, extrair conclusões a respeito do modo como a própria psicanálise se relaciona com o tema da educação. Além disso, o tema da educação pode também ser analisado pelo viés da crítica da ideologia social, uma vez que Žižek, por ser um filósofo de linhagem marxista e, como tal, um materialista dialético, contribui para instigar alguns pensamentos acerca disso. Desse modo, temos, portanto, uma análise que envolve tanto a crítica de cunho psicanalítico em relação ao tema da educação, como uma análise marxista sobre o modo como a educação torna-se, ela mesma, um mecanismo de alienação social vinculada à ideologia. Pensemos, pois, a educação entre essas duas matrizes de pensamento, procurando associá-la com o tema exposto ao longo do artigo.

Cabe frisar, antes de tudo, que a educação para a psicanálise é um empreendimento impossível. Impossível na medida em que o ideal de educação, desde a antiguidade, consiste na formação do indivíduo segundo um ideal de homem. Ora, a psicanálise é, justamente, o antípoda desse projeto. Não porque ela desacredita da possibilidade de formação humana, mas porque a própria ideia de formação espelhada num ideal de homem é a própria condição do adoecimento psíquico que ela visa explorar. A formação do sintoma é, pois, correlata à formação de um eu. E é exatamente esse ideal de um "eu, autônomo e racional", que fundamentou o projeto da educação no Iluminismo. Assim, a educação, para a psicanálise é, por definição, uma formação ortopédica, cujo resultado é a construção de indivíduos moldados segundo um ideal preestabelecido de antemão.

Podemos identificar a raiz desse projeto no nascimento mesmo da civilização ocidental. A ideia de educação enquanto formação tem sua origem na Paideia grega. Antes mesmo da organização em cidadesEstados, em sua fase agrária, os Gregos consolidaram sua cultura em torno de um ideal de Homem, o qual serviria de base para a formação do homem grego. As epopeias homéricas são, pois, a expressão de uma cultura 
forjada em torno de um ideal antropocêntrico, cujas divindades representam a plenitude do homem a ser conquistado por um processo de formação que deveria envolver, como horizonte último, uma série de virtudes (areté), tais como honra, coragem, sabedoria etc. Este mesmo ideal inspirou, muitos séculos depois, o movimento do romantismo alemão, que procurou recuperar o mesmo princípio de formação a partir do conceito de Bildung. Como o próprio termo diz (Bild/Imagem), a Bildung se refere a um processo de formação através de um quadro formativo que envolve, tal como na Paideia, um ideal de homem pleno, não fragmentado. Contudo, por Bildung não se deve confundir com o processo de educação metódico e racionalista próprio do projeto Iluminista da era moderna. A Bildung se contrapunha a esse projeto, porque, longe de pressupor uma ação metódica pela qual o indivíduo alcança um objetivo predeterminado, ela, como afirma Bruno Pucci, "pressupunha a atividade espontânea do indivíduo ao longo do aperfeiçoamento" (2011, p. 17).

A maior expressão literária desse princípio de formação pela Bildung é a obra de Goethe (2006), "Os anos de aprendizagem de Wilhem Meister". Sem entrar em detalhes sobre esse clássico da literatura, vale ressaltar que o propósito de Goethe é tematizar o processo de um ideal de formação aristocrático no seio de uma sociedade burguesa completamente esvaziada de sentido. A saga do herói do romance, em busca de uma formação plena, exprime, portanto, a derrocada da sociedade burguesa em conquistar valores transcendentais e absolutos. Contudo, a obra apresenta não a conquista desse ideal por parte do jovem burguês, mas justamente seu fracasso. E é exatamente nosso ponto onde nos encontramos: totalmente imersos numa sociedade administrada, fragmentada, alienada, mecanizada e esvaziada de sentido.

No entanto, a genialidade de Goethe não consiste em alimentar a nostalgia de um tesouro perdido no passado, mas o contrário. A fineza do pensamento do autor, ao trazer os impasses do processo de formação humana, é justamente mostrar que seu fracasso não reside simplesmente na estrutura formal de nossa sociedade, mas no próprio ideal de formação do homem enquanto um ideal a ser alcançado. O que se revela na passagem 
para a modernidade, isto é, da aristocracia para a sociedade burguesa, é não somente a impossibilidade de resgatar um ideal de homem pleno, mas o fato de que o próprio ideal já é problemático em si. Diante disso, o que podemos fazer em relação a um ideal que não pertence mais à forma estrutural de nossa organização social, mas a um passado que é, ele mesmo, uma ficção construída sobre uma sociedade de castas e desigual? Simplesmente desistir do ideal de formação humana? Evidentemente, essa seria a saída mais fácil - e, diga-se de passagem, é essa a saída que nossa sociedade vem adotando de forma cada vez mais acentuada.

O mérito da psicanálise foi não somente ter diagnosticado esse cenário, clinicamente falando, mas ao mesmo tempo ter proposto uma solução (se é que se trata de solução) para o impasse. E é nesse ponto que podemos analisar como que Žižek, a partir de sua orientação psicanalítica, pode pensar a educação. Assim, além de ser um filósofo de certa maneira vinculado ao contexto do pensamento crítico, por cuja análise podem-se vislumbrar os mecanismos sociais de alienação e reificação específicos do regime capitalista, ele não se deixa apanhar por uma concepção niilista a respeito do conceito de formação. Podemos, por isso, compreender, ao longo do que foi exposto sobre a sua perspectiva de materialismo dialético e luta de classes, que, embora o ideal de educação humana seja correlato de uma fantasia de totalidade de uma sociedade burguesa sem lacunas, é essa mesma sociedade que, ao abrir espaço para a luta de classes, nos possibilita pensar uma formação que não seja totalitária.

Em outros termos, assim como Goethe apresentou os impasses do jovem Wilheim Meister como impasses constitutivos da sociedade burguesa, buscar um ideal de totalidade no seio de uma sociedade fragmentada é, no fundo, o esforço dessa mesma sociedade em negar sua contradição imanente. Devemos, pois, problematizar o sentido de uma visão de mundo que idealiza a tradição como a era de ouro de um passado aurático. Segundo Žižek, a polarização entre um tempo presente corrompido e um passado virtuoso (ou vice-versa) é a condição sine qua non do processo ideológico. É, por assim dizer, o gozo totalitário dessa sociedade. Trata-se, pois, da insatisfação que produz seu próprio gozo. E, 
como vimos, isso provoca um círculo vicioso de mais-de-gozar pelo qual a insatisfação do gozo torna-se o gozo pela insatisfação. Em suma, o maisde-gozar se dá justamente pela impossibilidade de autofechamento, tornando-se assim, tanto inapreensível como inesgotável. Estamos, pois, diante de uma causa imanente à própria sociedade burguesa. E como pensar a educação a partir disso?

Devemos procurar compreender a formação não mais sob o princípio de identidade, seja da sociedade, seja do indivíduo. O que está em jogo desde o início é pensar o reconhecimento não com sua autoimagem ideal, mas com o resto inapreensível que mobiliza essa idealidade. Esse resto é o real da ideia de educação forjada a partir de um ideal de homem. Real que, apesar de não comparecer fenomenicamente, pôs em marcha todo o processo de formação desde a antiguidade até os dias de hoje. No entanto, esse ideal só pode ser concebido numa sociedade cujo antagonismo torna-se um problema epistemológico a ser solucionado.

Diante disso, a educação não deve mais espelhar-se num ideal de homem, mas no resto produzido pelas contradições constitutivas da sociedade moderna. Por isso, o termo de-formação é mais adequado para pensar esse processo formativo. Não que isso signifique a negação da educação, mas o contrário. Isso significa não mais cair na polaridade entre esclarecimento e barbárie. Se, como demonstraram Adorno e Horkheimer em "Dialética do Esclarecimento" (2006), a barbárie é constitutiva do esclarecimento, devemos assumir o processo formativo do homem não mais como um ideal de maturação do homem em relação à sua condição natural primitiva, mas sim a partir do reconhecimento com o elemento renegado que sustenta esse projeto emancipatório. A emancipação não é a negação das contradições em função de um horizonte de autossuficiência e autonomia, mas a identificação com isso que tal horizonte renega para existir. Somente assim a educação pode integrar no seu próprio conceito a ideia de luta de classes. E, talvez, seja isso que um verdadeiro ideal de Bildung queira (ou deva) significar. 


\section{Considerações finais}

O presente artigo teve como propósito apresentar a ideia de materialismo dialético em Slavoj Žižek associado ao conceito de luta de classes. O texto partiu da seguinte problemática: como é possível repensar a política (no seu sentido forte) na atualidade pós-política. Em outras palavras, o problema de fundo é basicamente saber como reapropriar-se do conceito de política como transformação social numa era cujo discurso dominante é o de que todas as condições e possibilidades de mudanças estruturais da sociedade estão exauridas. E, consequentemente, de que não há mais ideal ou ideologia a ser defendida, a não ser o individualismo hedonista das democracias liberais. Esse é mais ou menos o cenário em que nos encontramos desde o fim da Guerra Fria. Teóricos como Francis Fukuyama e Samuel Huntington, apesar de defenderem linhas de argumentações opostas, encontram-se retidos sob o mesmo domínio ideológico: o de que chegamos à era pós-ideológica e, como corolário dessa premissa, encontramo-nos já no fim da história.

Ironicamente, essa perspectiva, segundo Žižek, não é apenas um ponto de vista exclusivo da tradição liberal e conservadora, que aceita docilmente o capitalismo e as democracias liberais como o modelo acabado e intransponível das sociedades ocidentais. Este ponto de vista torna-se hoje a visão hegemônica também do lado das esquerdas. Ou seja, mesmo o campo da esquerda, de acordo com o filósofo, consente o capitalismo e as democracias parlamentaristas como ponto de chegada insuperável de nossa tradição. Ora, nessa perspectiva, Žižek sustenta que, apesar da ridicularização generalizada em torno da tese de Fukuyama sobre o fim da história - especialmente após os atentados de 11 de setembro, quando muitos analistas concluíram, precipitadamente, que o capitalismo havia chegado ao fim - há um acordo tácito que une esquerda e direita quando se trata da perpetuação do sistema capitalista. Por isso, é mais fácil, como sugere Žižek, aceitarmos a tese do fim do mundo do que a tese do fim do capitalismo. 
Isso sugere, portanto, que a ideia desenvolvida no presente artigo se encontra formulada numa perspectiva histórica. Pensar a luta de classes hoje é pensar uma história não factual, ou seja, uma história que se encontra para além dos fatos históricos propriamente ditos. Portanto, o grande desafio para a filosofia contemporânea consiste em compreender como articular outro conceito de história que não o sentido corrente de história como sucessão de fatos, e, a partir disso, repensar um sentido de política para além da política enquanto administração da vida social desvinculada da liberdade de mercado e da livre iniciativa. É nesse ponto que se encontra a proposta de Žižek e seu materialismo dialético. De acordo com Žižek, a acepção forte de história só pode ser concebida quando articulada ao conceito de luta de classes. Todavia não se trata de negar o atual estado de coisas e buscar no espírito de um marxismo ortodoxo o conceito de luta de classes. Esse conceito deve, sim, ser resgatado das cinzas, mas desde já transformado historicamente. O conceito não é apenas um esquema mental de compreensão da realidade. Ele deve ser tanto historicamente como ontologicamente rearticulado. Em outras palavras, convém extrair a forma da luta de classes lá onde ela parece não mais existir.

\section{Referências}

ADORNO, T. W.; HORKHEIMER, M. Dialética do Esclarecimento. Rio de Janeiro: Jorge Zahar, 2006.

BENJAMIN, W. Sobre o conceito da história. In: BENJAMIN, W. Magia e Técnica, Arte e Politica: ensaios sobre literatura e história da cultura. São Paulo: Brasiliense, 1996.

DERRIDA. Direção: Kirby Dick e Amy Ziering Kofman. San Francisco: Zeitgeist Video, 2002. $84 \mathrm{~min}$. Son, Color, Formato: $16 \mathrm{~mm}$.

FREUD, S. Além do Princípio do Prazer. In: FREUD, S. Obras completas, 
v. 14. São Paulo: Companhia das Letras, 2010.

FUKUYAMA, F. The End of History and the Last Man. New York: Free Prees, 1992.

GOETHE, J.W.V. Os anos de aprendizagem de Wilhelm Meister. São Paulo, editora 34, 2006.

HUNTINGTON, S. P. O choque de civilizações: e a recomposição da ordem mundial. Rio de Janeiro: Objetiva, 2010.

LÖWY, M. Walter Benjamin: aviso de incêndio- uma leitura das teses "Sobre o conceito de história". São Paulo: Boitempo, 2005.

PUCCI, B. Os anos de aprendizado de Wilhelm Meister e a questão da Bildung em Theodor Adorno. In: Theodor Adorno: diálogos filosóficos em educação, ética e estética. Passo Fundo: 2011.

ŽIŽEK, S. O mais sublime dos histéricos: Hegel com Lacan. Rio de Janeiro: Jorge Zahar, 1988.

ŽIŽEK, S. Eles não sabem o que fazem:o sublime objeto da ideologia. Rio de Janeiro: Jorge Zahar, 1992.

ŽIŽEK, S. As Metástases do Gozo: Seis Ensaios sobre a Mulher e a Causalidade. Lisboa: Relógio d'Água, 2006a.

ŽIŽEK, S. Elogio da Intolerância. Lisboa: Relógio d'Água, $2006 \mathrm{~b}$.

ŽIŽEK, S. A visão em paralaxe. São Paulo: Boitempo, 2008a.

ŽIŽEK, S. Enjoy Your Symptom! Enjoy your Symptom! Lacan in Hollywood and Out. New York/London: Routledge, 2008b.

ŽIŽEK, S. Órgãos sem Corpo: Deleuze e Conseqüências. Rio de Janeiro: Cia. de Freud, 2011. 
ŽIŽEK, S. Menos que Nada: Hegel e a sombra do materialismo dialético. São Paulo: Boitempo, 2012a.

ŽIŽEK, S. Vivendo no fim dos tempos. São Paulo: Boitempo, 2012b.

ŽIŽEK, S. O amor impiedoso (ou: Sobre a crença). Belo Horizonte: Autêntica, 2012c.

Data de registro: 09/02/2020

Data de aceite28/08/2020 